\title{
Lifetime changes of the oocyte pool: Contributing factors with a focus on ovulatory inflammation
}

\author{
Chan Jin Park ${ }^{1,2}$, Ji-Eun $\mathrm{Oh}^{1}$, Jianan Feng ${ }^{1}$, Yoon Min Cho ${ }^{1}$, Huanyu Qiao ${ }^{1}$, CheMyong Ko ${ }^{1}$ \\ 'Department of Comparative Biosciences, College of Veterinary Medicine, University of Illinois Urbana-Champaign, Urbana, IL; ${ }^{2}$ Epivara Inc., \\ Champaign, IL, USA
}

In mammalian species, females are born with a number of oocytes exceeding what they release via ovulation. In humans, an average girl is born with over a thousand times more oocytes than she will ovulate in her lifetime. The reason for having such an excessive number of oocytes in a neonatal female ovary is currently unknown. However, it is well established that the oocyte number decreases throughout the entire lifetime until the ovary loses them all. In this review, data published in the past 80 years were used to assess the current knowledge regarding the changing number of oocytes in humans and mice, as well as the reported factors that contribute to the decline of oocyte numbers. Briefly, a collective estimation indicates that an average girl is born with approximately 600,000 oocytes, which is 2,000 times more than the number of oocytes that she will ovulate in her lifetime. The oocyte number begins to decrease immediately after birth and is reduced to half of the initial number by puberty and almost zero by age 50 years. Multiple factors that are either intrinsic or extrinsic to the ovary contribute to the decline of the oocyte number. The inflammation caused by the ovulatory luteinizing hormone surge is discussed as a potential contributing factor to the decline of the oocyte pool during the reproductive lifespan.

Keywords: Atretic follicle; Folliculogenesis; Germ cells; Inflammation; Oocytes; Reproductive health

\section{The oocyte pool is the primary determinant of reproductive lifespan}

In women of reproductive age, the size of the oocyte pool (the total number of oocytes in the ovaries) is the primary predictor of fertility [1]. It is well established that the oocyte pool can be as large as a few million during the fetal stage, but decreases significantly to a million or less at birth. Here, we report the predicted patterns of

Received: September 3, 2021 · Revised: October 16, 2021 · Accepted: February 11, 2022 Corresponding author: Huanyu Qiao

Department of Comparative Biosciences, College of Veterinary Medicine, University of Illinois Urbana-Champaign, Urbana, IL 61802, USA

Tel: +1-217-300-5397 E-mail: hqiao@illinois.edu

Co-Corresponding author: CheMyong Ko

Department of Comparative Biosciences, College of Veterinary Medicine, University of Illinois Urbana-Champaign, Urbana, IL 61802, USA

Tel: +1-217-333-9362 E-mail: jayko@illinois.edu

*This study was supported by NIH HD094296 (CK), R00 HD082375 (HQ), and NSF SBIR 2052603 (CP).

This is an Open Access article distributed under the terms of the Creative Commons Attribution Non-Commercial License (http://creativecommons.org/licenses/by-nc/4.0/) which permits unrestricted non-commercial use, distribution, and reproduction in any medium, provided the original work is properly cited. change in the oocyte pool in humans and mice. The human predictions were made based on collective study reports published since 1960 and those that are currently available via PubMed (Figure 1A) [2-8]. Similarly, predictions were also made in mice because they are widely used as animal models for researching human fertility (Figure 1C) [9-18]. Briefly, the predictions in humans indicate that an ovary contains approximately 300,000 oocytes at birth $(600,000$ per person). The oocyte pool decreases in size throughout the entire reproductive lifespan, down to half by the onset of puberty and one-third by the age of 20. Interestingly, substantial variation in the oocyte pool size is seen by the age of 40 (Figure 1B), but this variation subsequently disappears. Eventually, the human oocyte pool becomes close to zero by the age of 50 years, when most women reach menopause. A similar declining pattern of the oocyte pool is also seen in mice, indicating that there is a regulatory mechanism that is common to both species.

There is a continuing trend worldwide for the current generation of women to plan to bear children at a considerably later time of life than in previous generations. This trend creates a risk that when the time to have a child arrives, the oocyte pool may not be large 


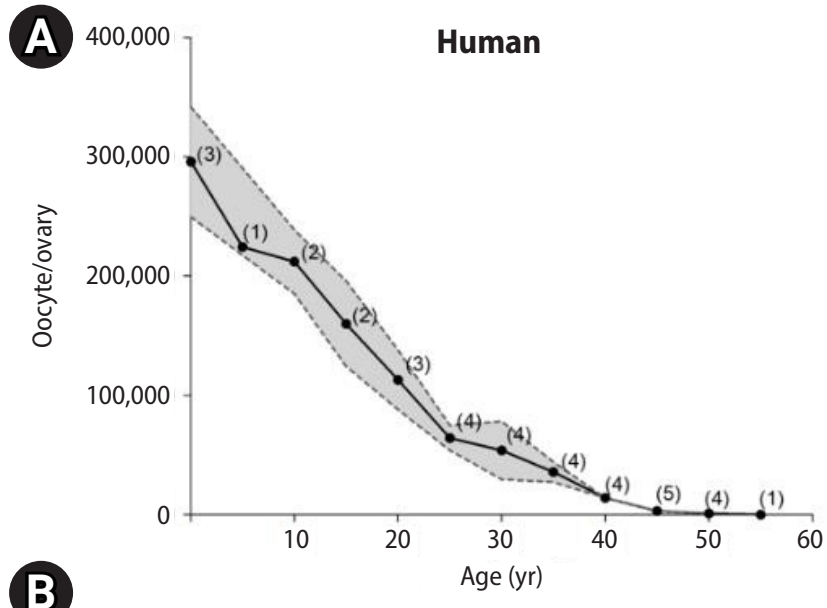

(B)
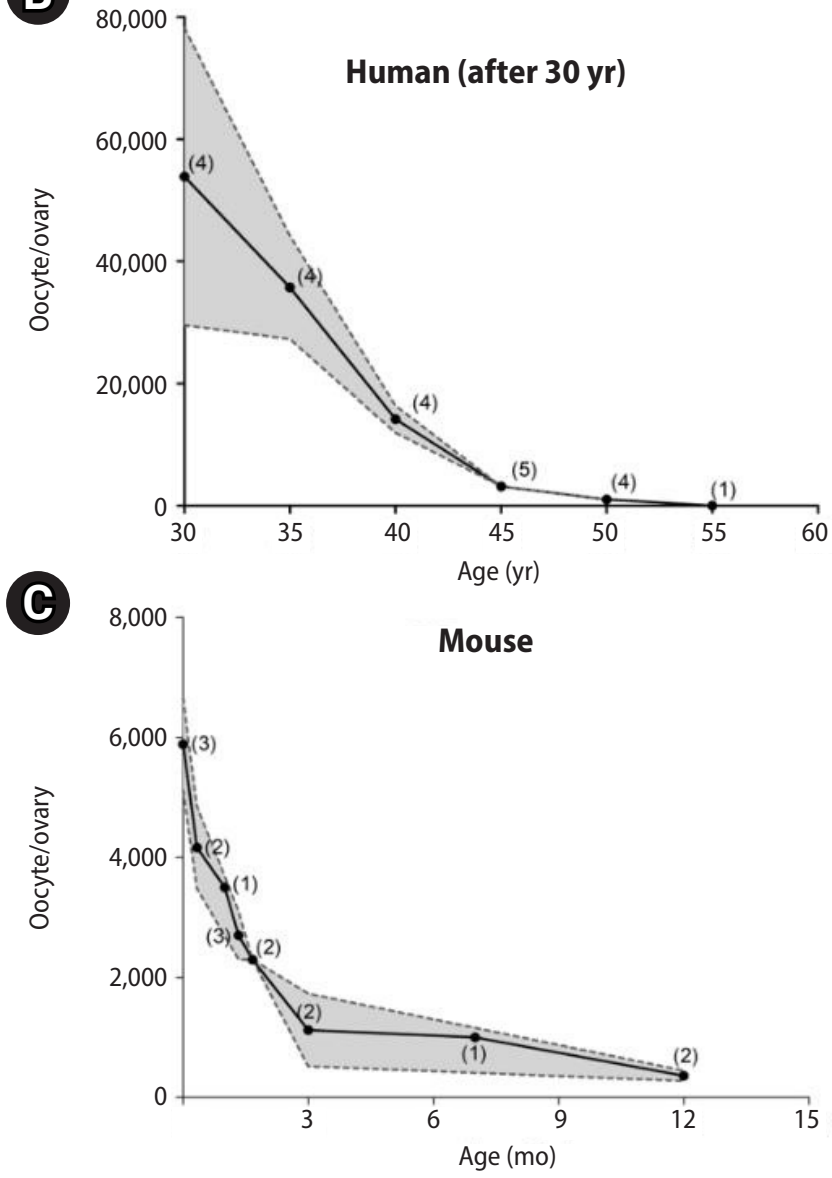

Figure 1. Lifetime changes in the oocyte pool in humans and mice. (A) The graph depicts the cumulative human data from the seven most relevant and reliable published articles that claim that oocyte counting was done in non-pathological ovaries. (B) This is a replica of the human oocyte pool, but only representing the age groups of 30-55 years. (C) The graph contains cumulative data collected from the 10 most relevant and reliable published articles. The reliability of published data was judged by an outlier test. The numbers in the parentheses are the numbers of articles used to calculate the average oocyte numbers in each age group. The gray area represents mean \pm standard error of the mean. Data analysis and graph-plotting were conducted using GraphPad Prism 5 (GraphPad Inc., La Jolla, CA, USA). enough to support fertility even with help from assisted reproductive technology. No method currently exists for precisely assessing the oocyte pool. Instead, a few methods are used as clinical assessments of the oocyte pool, including measurements of blood levels of anti-Müllerian hormone (AMH) alone or together with follicle-stimulating hormone, the levels of which are affected by the number of follicles in the ovary and the amount of estradiol synthesized by the follicles, respectively $[19,20]$. AMH is a peptide hormone produced by the granulosa cells of the primary and secondary follicles and released into the bloodstream. Therefore, the blood level of AMH is used as a proxy of the size of the oocyte pool, and this method has been adopted by most in vitro fertilization (IVF) clinics to assess the size of their patients' oocyte pool. Low or high blood AMH levels are used as a clinical marker to predict whether ovulation can be induced in an IVF patient or to determine how many oocytes can be retrieved upon inducing ovulation. However, neither AMH nor follicle-stimulating hormone levels are reflective of the actual size of the oocyte pool. Indeed, these levels do not change for the entire fertile lifespan even though the oocyte pool continues to decrease in size; they only begin to change when the oocyte pool becomes so small that not enough primordial follicles can be recruited to the growth phases. Interestingly, in a survey performed with 796 infertility clinics asking which test or factor best predicts fertility, $80 \%$ of respondents stated that age was the best predictor [21]. Why age? The oocyte pool decreases nonstop even when a woman's fertility is at its peak or she is in her teens or 20s. As of 2021, no consensus exists regarding the cause(s) of the continued decline of the oocyte pool, but it is believed to be a multifactorial phenomenon. In the following sections, we summarize reported causes of the decline that are backed by experimental or observational data. Additionally, the hypothesis that ovulatory inflammation is a contributing factor to the decline of the oocyte pool will be discussed.

\section{Contributing factors to the decline of the oocyte pool}

The peak size of the oocyte pool is established during fetal development, specifically during the transitional period of mid-to-late gestation [22]. Upon reaching the peak, the pool begins to decrease, primarily via a process called oocyte attrition, throughout the rest of the gestational period $[23,24]$. After birth, the oocyte pool continues to decrease due to a variety of factors including, but not limited to, follicular atresia, meiotic errors, ovulation, environmental toxicants, medical drugs, and possibly some other factors that are yet to be discovered (Figure 2). 


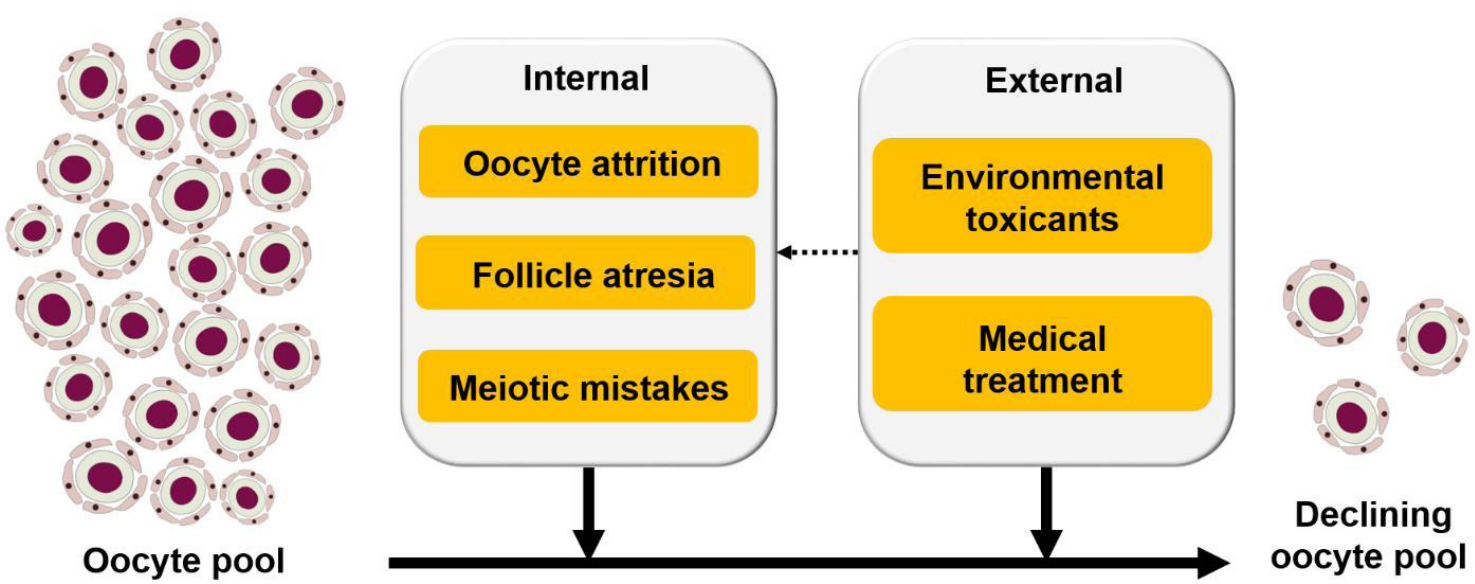

Figure 2. Contributing factors to the decline of the oocyte pool. Internal factors leading to the decline of the oocyte pool include oocyte attrition, follicular atresia, and meiotic errors. External factors, such as environmental toxicants and medical treatments, can either trigger internal factors or directly cause the reduction of the oocyte pool.

\section{Perinatal oocyte loss}

Immediately prior to or after birth, the ovary loses oocytes via oocyte attrition, which is mediated by immune cells infiltrating the fetal ovaries [25] or apoptosis triggered by DNA breaks [26,27]. Furthermore, autophagy, ferroptosis, and necrosis are also known to cause oocyte demise. Autophagy is a cell recycling pathway that involves the fusion of organelles with lysosomes for degradation [28-30]. Ferroptosis is a type of programmed cell death involving intracellular iron and oxidative phospholipids [22,31]. Necrosis is an inflammatory cell death process that results in swelling and eventually cell rupture [32].

\section{Follicular atresia}

After birth, a subset of dormant primordial follicles is recruited into a growth phase, which continues throughout the entire reproductive lifespan. Some of them grow and develop into preantral follicles, and eventually release oocytes via ovulation. However, the majority of the recruited follicles die during the growth phase; they eventually degenerate and are removed from the ovary. This phenomenon is called follicular atresia and is often triggered by the death of a granulosa cell in a follicle [22], eventually leading to the death of most granulosa cells and oocytes. Decreased estrogen production in the follicle or a milieu with increased androgen levels is a known cause of the initial death of granulosa cells [33-36]. In addition, erroneous signaling between the oocyte and granulosa cells also causes mis-regulation in the meiotic arrest of oocytes and follicular atresia [37-40].

\section{Environmental toxicants}

Humans are constantly exposed to environmental toxicants via in- halation, ingestion, or contact. Recent studies have shown that an alarming number of environmental toxicants can directly or indirectly damage oocytes. For example, oocytes in an ovary that is exposed to cadmium die due to an increased level of reactive oxygen species (ROS), subsequent DNA damage, and mitochondrial disruption in the oocytes [41]. Di(n-butyl) phthalate, an industrial plasticizer and stabilizer, kills oocytes by activating apoptosis pathways upon exposure in animals [42]. Nonylphenol, a commonly used industrial material similar to laundry detergents, has been shown to alter the expression of more than 800 genes in mouse oocytes, increase ROS levels, and eventually eliminate oocytes [43]. Further, a variety of endocrine-disrupting chemicals bind to steroid receptors (e.g., estrogen or progesterone receptors), synergistically disrupt hormonal balance, and directly or indirectly harm oocytes [44-46]. Unlike oocyte attrition and follicular atresia, which are mostly triggered by internal factors, environmental toxicants are from external sources and therefore preventable to some degree.

\section{Medical treatments}

Multiple drugs are used to cull harmful cells, particularly in cancer patients. These drugs primarily target cell-cycle regulators, making the ovary a vulnerable organ to such medical treatment. When given to a patient, these drugs inevitably impact cells in the ovary because a substantial proportion of ovarian cells undergo cell proliferation (granulosa cells in follicles at various stages) and meiosis (oocytes). Indeed, it is well known that young female cancer patients who receive chemotherapy suffer from premature ovarian insufficiency (POI) $[47,48]$. Chemotherapeutic drugs such as cyclophosphamide, cisplatin, vincristine, and doxorubicin are all reported to induce POI [49-51]. In addition to targeting cell cycle regulators, some chemo- 
therapeutic drugs "burn out" the oocyte pool. For example, cyclophosphamide stimulates follicle activation in oocytes and granulosa cells, thereby pushing an excessive number of primordial follicles into a growth phase and decreasing the oocyte pool [47]. Doxorubicin triggers the DNA-damaging TAp63a-Cleaved-CASP3 pathway to induce apoptosis in the oocytes of primordial follicles [48]. Radiation therapy is also toxic to oocytes. It increases ROS production in patients, which induces DNA damage either directly or via lipid peroxidation or by increasing the expression of a pro-apoptotic protein, p53 upregulated modulator of apoptosis, in oocytes or granulosa cells [52]. Cryopreservation of oocytes or ovarian tissues has been used to persevere oocytes for later use before chemotherapy [50]. Further, antioxidants such as melatonin are now used to quench ROS before radiation therapy [53].

\section{Meiotic errors}

Meiotic errors can be caused by environmental toxicants or medical treatments. However, they can also happen by chance during normal oogenesis. Typical meiotic mistakes include failure to repair DNA breaks and defective synapsis [26], abnormal spindle assembly [54], and further chromosome nondisjunction [55]. Surprisingly, $20 \%-25 \%$ of human oocytes obtained in IVF clinics showed aneuploidy [56], and the ratio increases as women become older [57]. To control the quality of the overall oocyte pool, certain meiotic checkpoint mechanisms sacrifice abnormal oocytes and decrease the total oocyte number $[54,57]$. However, these checkpoints are less stringent in females than in males [57]. Thus, some oocytes with meiotic errors can still be fertilized, leading to chromosome-related diseases/ syndromes such as Down syndrome in newborns $[58,59]$. Nonetheless, oocytes can find a way to efficiently repair DNA double-strand breaks and protect the genetic integrity of offspring if apoptosis is inhibited [60,61].

\section{Ovulatory inflammation: a contributing factor to the decline of the oocyte pool?}

Ovulation is the process of releasing oocyte(s) from the ovary. It is triggered by a preovulatory surge of luteinizing hormone $(\mathrm{LH})$ and recurs every reproductive cycle [62]. In the entire reproductive life span, a woman releases only 300-400 oocytes [63], a negligible subset of oocytes compared to the number of oocytes a female is born with. In the previous section, a few well-established causes of oocyte losses were reviewed. In this section, we will discuss another cause that may trigger oocyte loss: the acute inflammation that the ovary experiences at the time of ovulation. When a tissue undergoes acute inflammation, leukocytes quickly infiltrate the tissue and display a series of defensive behaviors with the aim of destroying foreign in- vaders, such as infectious microorganisms or harmful substances. However, these defensive actions inevitably damage the tissue itself. Overwhelming evidence indicates that the ovary experiences acute inflammation when it undergoes a cascade of ovulatory processes, suggesting that a similar tissue-damaging event may happen in the ovary at the time of ovulation. Therefore, the ovarian cells, including primordial germ cells, may be damaged and eventually removed from the ovary at each ovulation, accounting for a significant portion of oocyte loss during the reproductive lifespan. Herein, we will discuss this possibility.

\section{Ovulation is accompanied by acute inflammation}

The idea that ovulation is an inflammatory process was originally introduced in the early 1980s by Espey [64], who presented a striking similarity between a general inflammatory process and the events that take place at the time of ovulation. Since then, this idea has gained popularity through extensive observational and experimental data that were recently reviewed by Duffy et al. [65]. The most obvious evidence that the ovary undergoes acute inflammation is that the number and density of proinflammatory leukocytes increase in the ovary immediately after the LH surge [66-69], like any other tissue that undergoes acute inflammation. The $\mathrm{LH}$ surge-induced leukocyte infiltration is mediated by pro-inflammatory cytokines and ROS that are either released by ovarian cells or resident leukocytes [64,70-74]. For example, one of the pro-inflammatory cytokines, interleukin 1 beta (IL-1 $\beta$ ), is expressed and secreted from theca cells, granulosa cells, and leukocytes $[75,76]$. IL-1 $\beta$ subsequently induces the expression of prostaglandin synthase 2 (PTGS2) in granulosa cells [76]. PTGS2 is a rate-limiting enzyme in the synthetic pathway of prostaglandin E2 (PGE2) [77,78], a pro-inflammatory agent that impacts angiogenesis, blood flow, immune cell function, and tissue remodeling in the ovary [65]. Importantly, locally produced PGE2 stimulates the recruitment of a variety of proinflammatory cells to the ovary in a short time [79], as it does in other inflammatory sites [80], creating acute inflammation in the ovary.

\section{Ovulatory inflammation and tissue damage}

Acute inflammation causes oxidative stress and DNA damage in the resident cells, and this occurs in the ovary when it undergoes ovulatory processes [81-84]. As the ovary repeats ovulation, the ovarian tissue, including oocytes, may also be damaged by proinflammatory cells via engulfment and the proteases that the immune cells release [85]. Importantly, inflammatory cells and their secretions are primarily localized and execute their inflammatory actions around the blood vessels in the ovulatory follicles and medullary region. However, primordial follicles are sequestered in the cortex, the least 
vascularized region in the ovary. Therefore, presumably, the primordial follicles localized close to medulla, but not those far away from the inflammatory sites and in the cortex, may be damaged and lost at the time of ovulation (Figure 3).

In support of the suggested role of inflammatory cells in decreasing the oocyte pool, recent studies have pointed out that a pathological level of ovarian inflammation induces POI, which is caused by an accelerated decline of the oocyte pool [86-89]. For instance, wom- en with chronic systemic inflammation caused by an autoimmune disease (e.g., Addison disease) or by pathologically elevated production of inflammatory cytokines have a significantly higher likelihood of developing POI [87,90-93].

In addition to its direct impact on oocytes or follicles, inflammation may indirectly accelerate the decline of the oocyte pool by inducing fibrosis (deposition of connective tissue), which is generally observed in aged ovaries $[94,95]$. Indeed, fibrosis is a part of the natural aging

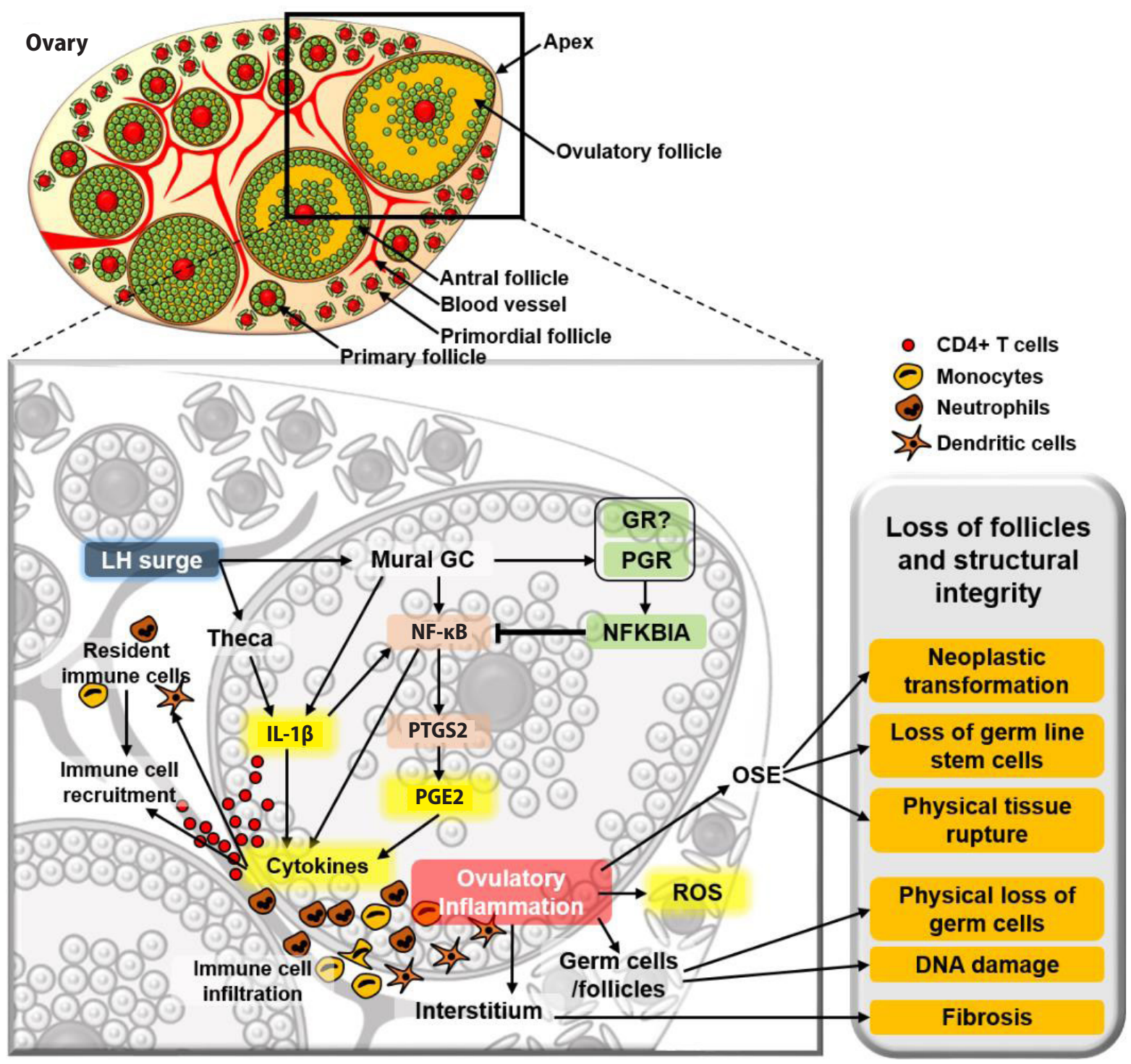

Figure 3. Ovulatory inflammation and the oocyte pool. The luteinizing hormone (LH) surge stimulates theca and mural granulosa cells (GCs) to produce prostaglandin E2 (PGE2) and interleukin 1 beta (IL-1 $\beta$ ), which then trigger them and resident immune cells to produce inflammatory cytokines. These cytokines increase pro-inflammatory immune cells in the ovary by facilitating their infiltration into the ovarian tissue from the circulating bloodstream, causing localized inflammatory situation in the ovary. As a result, germ cells and follicles may get damaged directly by the proinflammatory cells or indirectly via reactive oxygen species (ROS) produced by the immune cells or ovarian cells. The repeated ovulatory inflammation itself and physical tearing of the ovarian surface epithelium (OSE) result in both the loss of germ cells and neoplastic transformation. NF-KB, nuclear factor kappa-light-chain-enhancer of activated B cells; GR, glucocorticoid receptor; PGR, progesterone recepto; NFKBIA, NF-kB inhibitor alpha. 
process in the ovary and likely contributes to the decline of the oocyte pool, as fibrous tissues may interfere with normal ovarian dynamics, as well as impair follicular survival, recruitment, and growth (Figure 3).

\section{Polycystic ovarian syndrome, contraception, and the oocyte pool}

If it is true that ovulatory inflammation accounts for the loss of a significant portion of oocytes, and therefore is a contributing factor to the decline of oocyte pool, one can predict that the oocyte pool decreases more slowly and therefore the reproductive lifespan would be longer in women whose ovulation frequency or number is less than that of average women. Women with polycystic ovarian syndrome (PCOS) do not ovulate at all or have a much lower ovulation frequency than those without the syndrome. As a result, women with PCOS experience a significantly lower level of ovulatory inflammation. Indeed, women with PCOS have a larger ovarian pool and exhibit a slower rate of follicular atresia than infertile eumenorrheic women [96-98]. Another example of less ovulation can be seen in women who take contraceptive pills. Unfortunately, there is no direct evidence that taking contraceptive pills may delay the oocyte-pool decline. However, it is well established that women who take contraceptive pills have a lower probability of developing ovarian cancer than those who do not [99101], likely because the ovarian tissues have less exposure to ovulatory inflammation.

In summary, the literature clearly shows that the causes of the continuous decline of the oocyte pool throughout the entire reproductive lifespan are multifactorial. Some factors are intrinsic to the ovary (oocyte attrition, meiotic errors, follicular atresia) and unavoidable, while others are external and preventable (environmental toxicants, drugs). In addition, here, we discuss an additional potential intrinsic factor: ovulatory inflammation. The question remains of why females are born with excess oocytes. Might it be to ensure that they maintain fertility for a sufficient period when the ovary continues to lose oocytes due to the aforementioned reasons? Males are born without sperm in their gonads. Instead, their gonads contain germ cell stem cells, from which sperms are continuously produced for a few decades in humans, with the stem cells serving a reservoir for continued production of the male germ cells. The female gonads, however, do not contain germ cell stem cells; instead, ovarian egg production has to rely on the finite number of oocytes with which they are born. Therefore, having an excess number of oocytes at the time of birth may be a mechanism to ensure egg production for an extended period and long-term fertility in humans.

\section{Conflict of interest}

No potential conflict of interest relevant to this article was reported.

\section{ORCID}

Chan Jin Park
Ji-Eun Oh
Jianan Feng
Yoon Min Cho
Huanyu Qiao
CheMyong Ko

https://orcid.org/0000-0001-9008-1964 https://orcid.org/0000-0003-3352-9608 https://orcid.org/0000-0001-6987-1187 https://orcid.org/0000-0003-4278-8775 https://orcid.org/0000-0003-0966-8077 https://orcid.org/0000-0002-0963-3731

\section{Author contributions}

Conceptualization: CMK. Data curation: CJP, JEO, JF, YMC. Formal analysis: CJP, JEO, JF, YMC. Funding acquisition: CJP, HQ, CMK. Methodology: JEO, YMC, CMK. Project administration: HQ, CMK. Visualization: CJP, JF, JO, YC. Writing-original draft: all authors. Writing-review \& editing: CJP, $\mathrm{HQ}, \mathrm{CMK}$.

\section{References}

1. Pastore LM, Christianson MS, Stelling J, Kearns WG, Segars JH. Reproductive ovarian testing and the alphabet soup of diagnoses: DOR, POI, POF, POR, and FOR. J Assist Reprod Genet 2018;35:1723.

2. Block E. Quantitative morphological investigations of the follicular system in women; variations at different ages. Acta Anat (Basel) 1952; 14:108-23.

3. Block E. A quantitative morphological investigation of the follicular system in newborn female infants. Acta Anat (Basel) 1953;17:201-6.

4. Faddy MJ, Gosden RG. A mathematical model of follicle dynamics in the human ovary. Hum Reprod 1995;10:770-5.

5. Forabosco A, Sforza C. Establishment of ovarian reserve: a quantitative morphometric study of the developing human ovary. Fertil Steril 2007;88:675-83.

6. Gougeon A, Ecochard R, Thalabard JC. Age-related changes of the population of human ovarian follicles: increase in the disappearance rate of non-growing and early-growing follicles in aging women. Biol Reprod 1994;50:653-63.

7. Hansen KR, Knowlton NS, Thyer AC, Charleston JS, Soules MR, Klein NA. A new model of reproductive aging: the decline in ovarian non-growing follicle number from birth to menopause. Hum Reprod 2008;23:699-708. 
8. Richardson SJ, Senikas V, Nelson JF. Follicular depletion during the menopausal transition: evidence for accelerated loss and ultimate exhaustion. J Clin Endocrinol Metab 1987;65:1231-7.

9. Sonne-Hansen K, Nielsen M, Byskov AG. Oocyte number in newborn mice after prenatal octylphenol exposure. Reprod Toxicol 2003;17:59-66.

10. Pepling ME, Spradling AC. Mouse ovarian germ cell cysts undergo programmed breakdown to form primordial follicles. Dev Biol 2001;234:339-51.

11. Danilovich N, Sairam MR. Haploinsufficiency of the follicle-stimulating hormone receptor accelerates oocyte loss inducing early reproductive senescence and biological aging in mice. Biol Reprod 2002;67:361-9.

12. Fu X, Cheng J, Hou Y, Zhu S. The association between the oocyte pool and aneuploidy: a comparative study of the reproductive potential of young and aged mice. J Assist Reprod Genet 2014;31: 323-31.

13. Kerr JB, Duckett R, Myers M, Britt KL, Mladenovska T, Findlay JK. Quantification of healthy follicles in the neonatal and adult mouse ovary: evidence for maintenance of primordial follicle supply. Reproduction 2006;132:95-109.

14. Uri-Belapolsky S, Shaish A, Eliyahu E, Grossman H, Levi M, Chuderland $D$, et al. Interleukin-1 deficiency prolongs ovarian lifespan in mice. Proc Natl Acad Sci U S A 2014;111:12492-7.

15. Skaznik-Wikiel M, Tilly JC, Lee HJ, Niikura Y, Kaneko-Tarui T, Johnson J, et al. Serious doubts over "Eggs forever?". Differentiation 2007;75:93-9.

16. Johnson J, Canning J, Kaneko T, Pru JK, Tilly JL. Germline stem cells and follicular renewal in the postnatal mammalian ovary. Nature 2004;428:145-50.

17. Tamura H, Kawamoto M, Sato S, Tamura I, Maekawa R, Taketani T, et al. Long-term melatonin treatment delays ovarian aging. J Pineal Res 2017;62:e12381.

18. Miao Y, Cui Z, Gao Q, Rui R, Xiong B. Nicotinamide mononucleotide supplementation reverses the declining quality of maternally aged oocytes. Cell Rep 2020;32:107987.

19. Buyuk E, Seifer DB, Younger J, Grazi RV, Lieman H. Random anti-Mullerian hormone (AMH) is a predictor of ovarian response in women with elevated baseline early follicular follicle-stimulating hormone levels. Fertil Steril 2011;95:2369-72.

20. Weghofer A, Barad DH, Darmon SK, Kushnir VA, Albertini DF, Gleicher N. The ovarian sensitivity index is predictive of live birth chances after IVF in infertile patients. Hum Reprod Open 2020; 2020:hoaa049.

21. Tobler KJ, Shoham G, Christianson MS, Zhao Y, Leong M, Shoham Z. Use of anti-mullerian hormone for testing ovarian reserve: a survey of 796 infertility clinics worldwide. J Assist Reprod Genet
2015;32:1441-8.

22. Grive KJ. Pathways coordinating oocyte attrition and abundance during mammalian ovarian reserve establishment. Mol Reprod Dev 2020;87:843-56.

23. Malki S, van der Heijden GW, O'Donnell KA, Martin SL, Bortvin A. A role for retrotransposon LINE-1 in fetal oocyte attrition in mice. Dev Cell 2014;29:521-33.

24. Lei L, Spradling AC. Mouse oocytes differentiate through organelle enrichment from sister cyst germ cells. Science 2016;352:959.

25. Kaipia A, Hsueh AJ. Regulation of ovarian follicle atresia. Annu Rev Physiol 1997:59:349-63.

26. Hunter N. Oocyte quality control: causes, mechanisms, and consequences. Cold Spring Harb Symp Quant Biol 2017;82:235-47.

27. Qiao H, Rao HB, Yun Y, Sandhu S, Fong JH, Sapre M, et al. Impeding DNA break repair enables oocyte quality control. Mol Cell 2018; 72:211-21.

28. GawrilukTR, Hale AN, Flaws JA, Dillon CP, Green DR, Rucker EB 3rd. Autophagy is a cell survival program for female germ cells in the murine ovary. Reproduction 2011;141:759-65.

29. Song ZH, Yu HY, Wang P, Mao GK, Liu WX, Li MN, et al. Germ cell-specific Atg7 knockout results in primary ovarian insufficiency in female mice. Cell Death Dis 2015;6:e1589.

30. Zhihan T, Xinyi M, Qingying L, Rufei G, Yan Z, Xuemei C, et al. Autophagy participates in cyst breakdown and primordial folliculogenesis by reducing reactive oxygen species levels in perinatal mouse ovaries. J Cell Physiol 2019;234:6125-35.

31. Wang JJ, Ge W, Zhai QY, Liu JC, Sun XW, Liu WX, et al. Single-cell transcriptome landscape of ovarian cells during primordial follicle assembly in mice. PLoS Biol 2020;18:e3001025.

32. Marcinkiewicz JL, Krishna A, Cheung CM, Terranova PF. Oocytic tumor necrosis factor alpha: localization in the neonatal ovary and throughout follicular development in the adult rat. Biol Reprod 1994:50:1251-60.

33. Hatzirodos N, Irving-Rodgers HF, Hummitzsch K, Harland ML, Morris SE, Rodgers RJ. Transcriptome profiling of granulosa cells of bovine ovarian follicles during growth from small to large antral sizes. BMC Genomics 2014;15:24.

34. Hsueh AJ, Billig H, Tsafriri A. Ovarian follicle atresia: a hormonally controlled apoptotic process. Endocr Rev 1994;15:707-24.

35. Liu J, Du X, Zhou J, Pan Z, Liu H, Li Q. MicroRNA-26b functions as a proapoptotic factor in porcine follicular Granulosa cells by targeting Sma- and Mad-related protein 4. Biol Reprod 2014;91:146.

36. Manabe N, Goto Y, Matsuda-Minehata F, Inoue N, Maeda A, Sakamaki K, et al. Regulation mechanism of selective atresia in porcine follicles: regulation of granulosa cell apoptosis during atresia. J Reprod Dev 2004;50:493-514. 
37. Wigglesworth K, Lee KB, O’Brien MJ, Peng J, Matzuk MM, Eppig JJ. Bidirectional communication between oocytes and ovarian follicular somatic cells is required for meiotic arrest of mammalian oocytes. Proc Natl Acad Sci U S A 2013;110:E3723-9.

38. Alam MH, Miyano T. Interaction between growing oocytes and granulosa cells in vitro. Reprod Med Biol 2019;19:13-23.

39. Alam MH, Lee J, Miyano T. GDF9 and BMP15 induce development of antrum-like structures by bovine granulosa cells without oocytes. J Reprod Dev 2018;64:423-31.

40. Matsuda F, Inoue N, Manabe N, Ohkura S. Follicular growth and atresia in mammalian ovaries: regulation by survival and death of granulosa cells. J Reprod Dev 2012;58:44-50.

41. Cheng Y, Zhang J, Wu T, Jiang X, Jia H, Qing S, et al. Reproductive toxicity of acute $\mathrm{Cd}$ exposure in mouse: resulting in oocyte defects and decreased female fertility. Toxicol Appl Pharmacol 2019;379:114684.

42. Li FP, Zhou JL, Guo AW, Liu Y, Zhang F, Xu BH, et al. Di(n-butyl) phthalate exposure impairs meiotic competence and development of mouse oocyte. Environ Pollut 2019;246:597-607.

43. Xu Y, Sun MH, Xu Y, Ju JQ, Pan MH, Pan ZN, et al. Nonylphenol exposure affects mouse oocyte quality by inducing spindle defects and mitochondria dysfunction. Environ Pollut 2020;266(Pt 1):114967.

44. Goodman RL, Bittman EL, Foster DL, Karsch FJ. The endocrine basis of the synergistic suppression of luteinizing hormone by estradiol and progesterone. Endocrinology 1981;109:1414-7.

45. Bretveld RW, Thomas CM, Scheepers PT, Zielhuis GA, Roeleveld N. Pesticide exposure: the hormonal function of the female reproductive system disrupted? Reprod Biol Endocrinol 2006;4:30.

46. Farr SL, Cooper GS, Cai J, Savitz DA, Sandler DP. Pesticide use and menstrual cycle characteristics among premenopausal women in the Agricultural Health Study. Am J Epidemiol 2004;160:1194204.

47. Kalich-Philosoph L, Roness H, Carmely A, Fishel-Bartal M, Ligumsky H, Paglin S, et al. Cyclophosphamide triggers follicle activation and "burnout"; AS101 prevents follicle loss and preserves fertility. Sci Transl Med 2013;5:185ra62.

48. Wang Y, Liu M, Johnson SB, Yuan G, Arriba AK, Zubizarreta ME, et al. Doxorubicin obliterates mouse ovarian reserve through both primordial follicle atresia and overactivation. Toxicol Appl Pharmacol 2019;381:114714.

49. Morgan S, Anderson RA, Gourley C, Wallace WH, Spears N. How do chemotherapeutic agents damage the ovary? Hum Reprod Update 2012;18:525-35.

50. Spears N, Lopes F, Stefansdottir A, Rossi V, De Felici M, Anderson RA, et al. Ovarian damage from chemotherapy and current approaches to its protection. Hum Reprod Update 2019;25:673-93.
51. Winship AL, Carpenter M, Griffiths M, Hutt KJ. Vincristine chemotherapy induces atresia of growing ovarian follicles in mice. Toxicol Sci 2019;169:43-53.

52. Mishra B, Ripperdan R, Ortiz L, Luderer U. Very low doses of heavy oxygen ion radiation induce premature ovarian failure. Reproduction 2017;154:123-33.

53. Malott KF, Luderer U. Toxicant effects on mammalian oocyte mitochondria. Biol Reprod 2021;104:784-93.

54. Lane S, Kauppi L. Meiotic spindle assembly checkpoint and aneuploidy in males versus females. Cell Mol Life Sci 2019;76:1135-50.

55. Fragouli E, Wells D, Delhanty JD. Chromosome abnormalities in the human oocyte. Cytogenet Genome Res 2011;133:107-18.

56. Hassold T, Hunt P. To err (meiotically) is human: the genesis of human aneuploidy. Nat Rev Genet 2001;2:280-91.

57. Nagaoka SI, Hassold TJ, Hunt PA. Human aneuploidy: mechanisms and new insights into an age-old problem. Nat Rev Genet 2012;13:493-504.

58. Ghosh S, Hong CS, Feingold E, Ghosh P, Ghosh P, Bhaumik P, et al. Epidemiology of Down syndrome: new insight into the multidimensional interactions among genetic and environmental risk factors in the oocyte. Am J Epidemiol 2011;174:1009-16.

59. Zheng CJ, Byers B. Oocyte selection: a new model for the maternal-age dependence of Down syndrome. Hum Genet 1992;90:16.

60. Bolcun-Filas E, Rinaldi VD, White ME, Schimenti JC. Reversal of female infertility by Chk2 ablation reveals the oocyte DNA damage checkpoint pathway. Science 2014;343:533-6.

61. Stringer JM, Winship A, Zerafa N, Wakefield M, Hutt K. Oocytes can efficiently repair DNA double-strand breaks to restore genetic integrity and protect offspring health. Proc Natl Acad Sci U S A 2020;117:11513-22.

62. Tsafriri A, Reich R. Molecular aspects of mammalian ovulation. Exp Clin Endocrinol Diabetes 1999;107:1-11.

63. Mastroianni L, Coutifaris C. The FIGO manual of human reproduction. Vol 1. Reproductive physiology. Park Ridge: Parthenon Publishing; 1990.

64. Espey LL. Ovulation as an inflammatory reaction: a hypothesis. Biol Reprod 1980;22:73-106.

65. Duffy DM, Ko C, Jo M, Brannstrom M, Curry TE. Ovulation: parallels with inflammatory processes. Endocr Rev 2019;40:369-416.

66. Bukulmez O, Arici A. Leukocytes in ovarian function. Hum Reprod Update 2000;6:1-15.

67. Fleming JS, Beaugie CR, Haviv I, Chenevix-Trench G, Tan OL. Incessant ovulation, inflammation and epithelial ovarian carcinogenesis: revisiting old hypotheses. Mol Cell Endocrinol 2006;247:4-21.

68. Oakley OR, Kim H, El-Amouri I, Lin PC, Cho J, Bani-Ahmad M, et al. Periovulatory leukocyte infiltration in the rat ovary. Endocrinolo- 
gy 2010;151:4551-9.

69. Yamada M, Gentry PA. Hemostatic profile of bovine ovarian follicular fluid. Can J Physiol Pharmacol 1995;73:624-9.

70. Shukovski L, Tsafriri A. The involvement of nitric oxide in the ovulatory process in the rat. Endocrinology 1994;135:2287-90.

71. Yamauchi J, Miyazaki T, Iwasaki S, Kishi I, Kuroshima M, Tei C, et al. Effects of nitric oxide on ovulation and ovarian steroidogenesis and prostaglandin production in the rabbit. Endocrinology 1997; 138:3630-7.

72. Jablonka-Shariff A, Olson LM. The role of nitric oxide in oocyte meiotic maturation and ovulation: meiotic abnormalities of endothelial nitric oxide synthase knock-out mouse oocytes. Endocrinology 1998;139:2944-54.

73. Ness RB, Cottreau C. Possible role of ovarian epithelial inflammation in ovarian cancer. J Natl Cancer Inst 1999;91:1459-67.

74. Kodaman PH, Behrman HR. Endocrine-regulated and protein kinase C-dependent generation of superoxide by rat preovulatory follicles. Endocrinology 2001;142:687-93.

75. Park CJ, Lin PC, Zhou S, Barakat R, Bashir ST, Choi JM, et al. Progesterone receptor serves the ovary as a trigger of ovulation and a terminator of inflammation. Cell Rep 2020;31:107496.

76. Gerard N, Caillaud M, Martoriati A, Goudet G, Lalmanach AC. The interleukin-1 system and female reproduction. J Endocrinol 2004;180:203-12.

77. Needleman P, Turk J, Jakschik BA, Morrison AR, Lefkowith JB. Arachidonic acid metabolism. Annu Rev Biochem 1986;55:69-102.

78. DeWitt DL. Prostaglandin endoperoxide synthase: regulation of enzyme expression. Biochim Biophys Acta 1991;1083:121-34.

79. Jabbour HN, Sales KJ, Catalano RD, Norman JE. Inflammatory pathways in female reproductive health and disease. Reproduction 2009;138:903-19.

80. Ricciotti E, FitzGerald GA. Prostaglandins and inflammation. Arterioscler Thromb Vasc Biol 2011;31:986-1000.

81. Murdoch WJ, Townsend RS, McDonnel AC. Ovulation-induced DNA damage in ovarian surface epithelial cells of ewes: prospective regulatory mechanisms of repair/survival and apoptosis. Biol Reprod 2001;65:1417-24.

82. Savant SS, Sriramkumar S, O'Hagan HM. The role of inflammation and inflammatory mediators in the development, progression, metastasis, and chemoresistance of epithelial ovarian cancer. Cancers (Basel) 2018;10:251.

83. Jia D, Nagaoka Y, Katsumata M, Orsulic S. Inflammation is a key contributor to ovarian cancer cell seeding. Sci Rep 2018;8:12394.

84. Yang-Hartwich Y, Gurrea-Soteras M, Sumi N, Joo WD, Holmberg JC, Craveiro V, et al. Ovulation and extra-ovarian origin of ovarian cancer. Sci Rep 2014;4:6116.

85. Spanel-Borowski K. Ovulation as danger signaling event of innate immunity. Mol Cell Endocrinol 2011;333:1-7.

86. Lliberos C, Liew SH, Zareie P, La Gruta NL, Mansell A, Hutt K. Evaluation of inflammation and follicle depletion during ovarian ageing in mice. Sci Rep 2021;11:278.

87. Huang Y, Hu C, Ye H, Luo R, Fu X, Li X, et al. Inflamm-aging: a new mechanism affecting premature ovarian insufficiency. J Immunol Res 2019;2019:8069898.

88. Navarro-Pando JM, Alcocer-Gomez E, Castejon-Vega B, Navarro-Villaran E, Condes-Hervas M, Mundi-Roldan M, et al. Inhibition of the NLRP3 inflammasome prevents ovarian aging. Sci Adv 2021;7:eabc7409.

89. Yang L, Chen Y, Liu Y, Xing Y, Miao C, Zhao Y, et al. The role of oxidative stress and natural antioxidants in ovarian aging. Front Pharmacol 2021;11:617843.

90. Sammaritano LR. Menopause in patients with autoimmune diseases. Autoimmun Rev 2012;11:A430-6.

91. Reato G, Morlin L, Chen S, Furmaniak J, Smith BR, Masiero S, et al. Premature ovarian failure in patients with autoimmune Addison's disease: clinical, genetic, and immunological evaluation. J Clin Endocrinol Metab 2011;96:E1255-61.

92. Coulam CB, Stern JJ. Immunology of ovarian failure. Am J Reprod Immunol 1991;25:169-74.

93. Naz RK, Thurston D, Santoro N. Circulating tumor necrosis factor (TNF)-alpha in normally cycling women and patients with premature ovarian failure and polycystic ovaries. Am J Reprod Immunol 1995;34:170-5.

94. Rybinski B, Franco-Barraza J, Cukierman E. The wound healing, chronic fibrosis, and cancer progression triad. Physiol Genomics 2014;46:223-44.

95. Wynn TA, Ramalingam TR. Mechanisms of fibrosis: therapeutic translation for fibrotic disease. Nat Med 2012;18:1028-40.

96. Mellembakken JR, Berga SL, Kilen M, Tanbo TG, Abyholm T, Fedorcsak P. Sustained fertility from 22 to 41 years of age in women with polycystic ovarian syndrome. Hum Reprod 2011;26:2499504.

97. Webber LJ, Stubbs SA, Stark J, Margara RA, Trew GH, Lavery SA, et al. Prolonged survival in culture of preantral follicles from polycystic ovaries. J Clin Endocrinol Metab 2007;92:1975-8.

98. Wiser A, Shalom-Paz E, Hyman JH, Sokal-Arnon T, Bantan N, Holzer $\mathrm{H}$, et al. Age-related normogram for antral follicle count in women with polycystic ovary syndrome. Reprod Biomed Online 2013; 27:414-8.

99. Iversen L, Fielding S, Lidegaard O, Morch LS, Skovlund CW, Hannaford PC. Association between contemporary hormonal contraception and ovarian cancer in women of reproductive age in Denmark: prospective, nationwide cohort study. BMJ 2018;362: k3609. 
100. Auphan N, DiDonato JA, Rosette C, Helmberg A, Karin M. Immunosuppression by glucocorticoids: inhibition of NF-kappa B activity through induction of I kappa B synthesis. Science 1995; 270:286-90.
101. Barkan D, Jia H, Dantes A, Vardimon L, Amsterdam A, Rubinstein M. Leptin modulates the glucocorticoid-induced ovarian steroidogenesis. Endocrinology 1999;140:1731-8. 